\title{
Determinants of technical efficiency of Slovenian farms
}

Štefan Bojnec * and Laure Latruffe ** P. $*$ University of Primorska, ** INRA Rennes

Motivation: To shed light on how farm performance might evolve and on which farms will possibly survive the international competition post-accession

Methods: Farm performance is studied from the point of view of technical efficiency Calculated with stochastic frontier and non-parametric Data Envelopment Analysis (DEA)

Data: FADN, 1994-2003, family farms

\section{Results:}

- both methods give consistent results

- initial large inefficiencies (degree of technical

Figure: Evolution of technical efficiency calculated with efficiency increased from 0.5 to 0.8 )

- a jump in efficiency prior the EU accession

- farm specialisation is a crucial determinant for increasing technical efficiency

- negative impact of farm commercialisation due to intra-farm intermediary consumption in livestock production

- negative influence of public support DEA (TE DEA) and with stochastic frontier (TE stochastic)

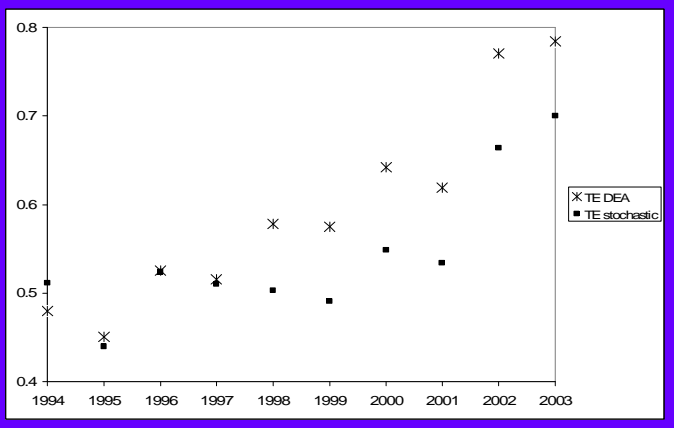

\begin{tabular}{|c|c|c|c|c|}
\hline & \multicolumn{2}{|c|}{$\begin{array}{l}\text { Determinants of technical inefficiency } \\
\text { calculated with stochastic frontier }\end{array}$} & \multicolumn{2}{|c|}{$\begin{array}{l}\text { Determinants of technical efficiency } \\
\text { calculated with DEA }\end{array}$} \\
\hline & coefficient & significance & coefficient & significance \\
\hline Constant & -0.110 & $* * *$ & 0.870 & $* * *$ \\
\hline Share of hired labour & -0.298 & & 0.002 & \\
\hline Share of rented land & -0.178 & & 0.001 & ** \\
\hline Share of marketed output & 0.225 & $* * *$ & -0.006 & $* *$ \\
\hline Herfindahl specialisation index & -0.263 & $*$ & 0.206 & $* * *$ \\
\hline Production subsidy to revenue ratio & 0.214 & $* * *$ & -1.090 & $* * *$ \\
\hline Time trend & -0.472 & $* * *$ & 0.032 & $* * *$ \\
\hline Log likelihood & \multicolumn{2}{|c|}{25.60} & \multicolumn{2}{|c|}{134.05} \\
\hline
\end{tabular}

$* * * 1$ percent level of significance; $* * 5$ percent level of significance; $* 10$ percent level of significance

Conclusions: technical efficiency growth might slow down after accession due to increased support; but positive influence of public support can be expected on technological change, and thus on farm productivity

Future research: impact of the EU accession on farm productivity 